\title{
LA PRACTICA DEL ECONOMISTA EN TORNO A LA SOCIEDAD COLOMBIANA
}

Javier Humberto Restrepo Zea *

\section{Introducción}

El presente ensayo constituye un nuevo aporte a las reflexiones sobre la formación y el papel del economista. Su propósito lundamental consiste en relacionar realidad colombiana y desempeño profesional.

En los diferentes tópicos tratados al interior del texto se insiste en la espectalización de la universidad pủblica en los ramos del sector público, la investigación y la plarificación. Se llama tambièn la atención por desbordar el economicismo y practicar la economia en el marco de las ctencias sociales y la investigación participativa.

Las conclusiones que se desprenden de esta reflexiôn pueden agruparse en dos niveles: de un lado. se reclaman algunos ajustes en la formación del economista tendientes a hacer más compatible las caracteristicas del egresado con la demanda del medio; del otro, se llama la atención sobre la necesidad de construlr una éttca profestonal en tomo a los principios fundamentales que surgen de una sociedad en movimiento.

\section{Un perfil para el econo- mista}

Teniendo en cuenta los aspectos señalados sobre la formación del economista y el desenvolvimiento social, en esta parte se presentanalgunos tópicos relacionados con el economista que se requiere en el futuro, los cambios necesarios en la formación profestonal y el papel de las asociaciones de economistas. 


\section{Demanda futura por eco- nomistas}

El campo de acción del economista se encuentra demarcado por tres tipos de actfuidades generales, cada una de las cuales posee una graduación de acuerdo con la complejidad, el sector económico y su vinculación con la politica. En un cuarto orden se encontrarian aquellas actividades comunes a las cuales ingresarian los economistas rechazados en el mercado profesional. Las tres actividades son: docencia, investigación y administracion $y$ dirección.

Antes de senalar algunos aspectos sobre esta úlitima. insistase en su articulación a las seriales emittdas por el sector público y el interés de los particulares por adaptarse a sus decisiones y provocar la adopeión de las más convenientes. Milton Friedman, un defensor del liberalismo económico. apunta en forma acertada la influencia de los economistas sobre la politica pública $^{1}$ y la vinculaciòn profesional de aquellos en función de esta última. El economista, según Friedman, puede actuar como informador (léase publicista), tratando de convencer a la gente sobre la conveniencia de una determinada politica; como analista de los cambios en acuerdos instltucionales. el economista habrá de diseñar los mecanismos de adopción; finalmente, los economistas pueden actuar como presentadores de opciones para la crisis. La articulación del econiomista con el gobierno es presentada por Friedman asi:

-En términos generales, el gobierno es una importante fuente de empleo para nosotros (las economistas). tanto directamente como a través de la inversion gubernamental en las empresas privadas [...) también otras intervenciones gubernamentales generan empleo para nosotros en las empresas privadas que desean calcular los efectos de dichas intervenciones y contar con argumentos para de. fender los cambios favorables a determinados ramos empresariales ${ }^{2}$,

Se ve, pues, cốmo la labor del economista se encuentra inserta en la función macroeconómica del Estado y, por extension, en la percepción del funcionamiento del mercado. Ahora bien, si la tendencia actuales a la liberalización de la economia, ¿cómo entender que habrá $\mathrm{cm}$ pleopara los economistas?
El desmonte de trabas al libre ejercicto de actividades económicas, la descentraización del Estado y el propósito de privatizar algunas empresas estatales y funciones públicas conllevan al diseno de estrategias y politicas desde las unidades economicas que antes simplemente actuaban en funcion de las disposiciones oficiales. Ahora el economista debe actuar como el asesor por excelencia del accionar de una determinada unidad sobre el conjunto del mercado: el economista, sabemos. es quien domina analitica y conceptualmente lo que hay por fuera de esa unidad.

En sintests, la liberacion genera la necesidad individual de percibir los cambios exógenos y actuar de acuerdo con la politica gubernamental. E1 economista, de tal modo, ha de ser empleado por empresas privadas ${ }^{3}$ o públicas para disenar su desenvolvimientoy maximizar elaprovechamiento desus recursos. Adicionalmente. frente a las funclones de asesoria y consultoria se abre.paso el ejercicio de actividades por cuentapropla, de modo que el profesional atiende la demanda de varias empresas que por sus caracte-

1. Friedman, Miltorr Economistas y politicas económieass.

2 lbsd.

3. En el pertódico El Tempo de febrero 17 de 1991 ae habla de un tricremento en la contratackon de economistas en la empresa privada a causa de las medidas de liberalización. 
tisticas no necesitan de su presencia permanente.

A través de este marco general se muestra una dermanda por economistas para el manejo de las tendencias liberacionistas. Para conquistar un mercado el economista habra de especializarse en un campo específico de modio que pueda acceder a la câtedra y a la prestación de asesorias y consultorias. Refleranse entonces los carmpos tributario. financiero, evaluación de proyectos, plantficación y sectorial (empleo, finanzas públicas, etc].

Además de estas referenclas a una demanda libre. es importante tener en cuenta las perspectivas desatadas por la ley 37 de 1990 en torno a una demanda atada, ya que se hace exclusivo del economista la realización de un buen nummero de actividades. Esta ley, además, constituye un avance en la reglamentación de la profesion al crear un Consejo Nacional Profesional de Economia encargado de expedir matricula profesional y conocer faltas a la ética; tamblén reconoce a la Socledad Colombiana de Economistas como organo con. sultor del Gobierno Nacional en la elaboración de los planes y programas de desarrollo económico y soctal.
La ley 37 señala la actuación de un economista en los siguientes casos:

1. Cargo de decano en las facultades de economia.

2. Cátedras básicas de economía en los programas académicos aprobados por el Gobierno Nacional.

3. Elaboración de los siguientes estudios:

Factibilidad economica y social.

- Inversiones de capltal extranjeroen el pais. - Asignación de precios. tasas. tarifas y subsidios.

- Valores comerciales. gravámenes arancelarlos y tarifas varias de importaciōn.

4. Elaboración de los planes de desarrollo económico y social nacionales, regionales, departamentales, municipales, distritales $y$ sectoriales.

5. Certificación de la variablidad económica y social en la elaboración y evaluación de proyectos de inversion público y privado.

6. Presentación de solicitudes de créditos de fomento para financiar proyectos de inversión.

7. Presentación de solicltudes para utllizar los sistemas especiales de importación-exportación y de intercambio comercial que deban presentarse para su aprobación ante
INCOMEX, PROEXPO. Dirección General de Aduanas.

\section{Cambios en la formacion profesional}

Estas caracteristicas de la demandapor economistas. y las consideraciones anotadas acerca de la realidad colombiana, permiten reaHzar algunas sugerencias para ajustar la formación profesional a estos requerimientos.

En primer lugar, para que el economista pueda ingresar al manejo de las nuevas tendencias, los planes de estudio deberán presentar algunas modificacionescon las cuales se adopten tales tendenclas. Asi, en forma compatible con una descentralización estatal, habrá de producirse una descentralización en los enfoques; por ejemplo, las finanzas puiblicas deben reducirse hastasu nivellocal, $y$ hay que insistir en el es. tudio de la economia espa. cial, frente a lo cual debe desarrollarse la idea de la mesoeconomia o economia intermedia entre lo macro y lo microeconómico.

Otro aspecto importante a tener en cuenta es el relacionado con el tema de la planificación y lo que puede denominarse el enfoque del proyecto. La evaluación de proyectos, articulada a los sistemas de planeación, constituyen gran punto de interés en la actualidad. 
En segundo lugar, la formacion del economista deberá tener una orientación socialy de proyección cludadana, de modo que el profestonal sea participe de los procesos soctales y politicos reinantes, a la vez que se integre a la comunidad con una optica participante para construir los diferentes proyectos que demanden su acción.

En tercer lugar, para darle vigor a la formación desde un punto de vista práct!co, proyectar la unitverstdad $\mathrm{c}$ iniciar al economis. ta en su desempeño profesional, es importante avanzar en la institucionalización de una pràctica pre-profesional dirigida a los principales campos de acción identificados en este ensayo. Piénsese, por ejemplo. en la cantidad de trabajos que pueden realizarse en materia de tarifas de servicios públicosen los municipios, o la evaluación de proyectos o montaje de sistemas de información y de planeactón del sector público y privado. Los beneficios de esta práctica son para la respectiva entidad, la universidad y el estudiante; ademâs, es una forma de conquistar espacios y competir por ellos frente a otras profesiones. con lo cual se muestrala proyeccion real de un economista.

Finalmente, para dar indcio a la especfalzación requerida para entrar en el mercado de las asesorias, consultorias y cátedras. durante los últimos semestres deberán diseñarse unos bloques de estudio optatlvos para que el estudiante se ublque en el de su preferencla.

\section{El papel de las Asocta- clones de Economistas}

Además de los derechos que la ley pueda otorgarle a las Asociaciones de Economistas para hacer parte de los Consejos Professonales y, a través de ellos. conocoery pedir las sanción respectiva a las faltas contra la ética profesional, tales Asociaciones deberian liderar la revisión permanente al proceso de formulación acá presentado de manera sistémica. Las asociaciones conocen de algún modo el funcionamiento del mercado profesional. Con esta base pueden detectar las fallas tanto estructurales como coyunturales para retroalimentar la formación profesional y la capacitación permanente de sus asociados.

\section{El proceso de formación del economista}

La formación profesional puede entenderse en el marco de un enfoque sistémico, y no solamente de insumo-producto, ya que deben considerarse en forma permanente las interrelaciones entre la universidad y su entomo. asi como la práctica del feed-back que indique los cambios y ajustes necesartos en alguna de las etapas del proceso a fin de mantener compatibles las necesidades y demandas del mercado con la oferta profestonal.

Para analbar el proceso de formación del economista conviene diferenciar tres fases fundamentales enlas cuales éste toma un nombre determinado: aspirante, estudlante y profesional, respectivamente. El producto de ello será la ocupación del economista en un campo de acción proplo de su disciplina, o la desocupación profesional encubierta en clerto tipo de actividades comunes.

Puede tomarse como eje central del proceso a la universidad püblica, la cual contituye una unidad productiva que recibe un insumo para transformar durante un periodo relativamente largo, aunque por sus caracteristicas institucionales4 esa capaci-

4 Podrian mencionarse: La carencia de una politica sobre los aspectos basions de la formacion proíesional y el ejercicio de la libertad de catedra, quec conllevan una desarticulación de las díferentes asignaturas con los programas acadé: micos. 
dad de transformación resulte minimizada y sujeta a la interrelación entre individuos $y$ la militancia politien y religlosa. el aspirante será quien desee ingresar al programa de economia, y luego de su ingreso consolide su vas. piracion-aser economista. Esta pude ser la fase mâs dura para el sujeto y produce las mayores fugas [đeserctón y reprobación) como consecuencia de un choque entre las creencias que se tienen sobre la carrera y las capacidades y actitudes del aspirante: no es facll combinar el estudio matematico, la lectura cientifica y el analisis abstracto.

Los aspirantes al programa de economía están clasificados a partir de dos criterios básicos, los cuales van a condicionar la produccéón cualitativa del economista. Son ellos: estratificación y motivación. La estratificación puede entenderse en los aspectos socioeconómicos e intelectuales: a partir de ellos el aspirante mostrará en buena medida la capacidad de adaptación a los requerimientos acadérnicos y psicológicos, y será determinante el cociente intelectual establecido desde sus estudios anteriores.

La motivación hace relación al interés que tiene el aspirante por convertirse en economista; se distinguen, entonces: los convencidos, los cuales poseen la idea tnquebrantable de estudiar economiay acceden rảpidamente a su aprendizaje; los indecisos, que escojen el programa sin estar seguros de su aceptación en el tlempo; y los casuales, que llegan a la carrera debido a una escogencia aleatoria o como consecuencia de la segunda opción que ofrecen varias unlversidades. La segunda fase, en la cual ordinariamente se entiende el proceso de formación, el estudiante rectbe todos los elementos indispensables para su posterior desempeno profesional y puede ser inducido a la especialización en determinada materia. En esta fase se requiere una interrelación muy clara de la universidad con el medio, tanto en los aspectos laborales como de la realidad social, con el propósito de producir el economista requerido. Puede presentarse, como consecuencla de la falta de tal interrelación, un desface entre el profesional y la demanda del medio.

Finalmente, la fase de graduactón y desempeno profesional sugiere la clasificación de su producto

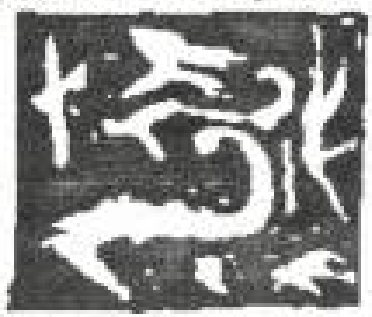

humano de acuerdo con la calidad delmismo. Se trata de establecer un fraccionamiento de la oferta profesional en tres niveles: economistas de primera calidad, los cuales no tendrán problemas de empleoy serán absorbidos rápidamente por los movimientos de demanda: nomistas de nivel medio, quienes podrain responder a su ejercicio profesional pero tendrán una deman. da inferior y estarán sujetos a desempleo temporal; por último, habrá unos economistas de rechazo, los cuales constitutràn una sobreoferta profesional debido a que no se presentará ninguna demanda inferior y el ajuste se presentard a través de un empleo para no economistas.

Estos resultados son producto básicamente de la clasificación de los aspirantes y del grado de interrelación de la universidad con el medio. Cuando se quiera influenciar dichos resultados será necesario, en general, aumentar el grado de permeabilidad de la universidad para construir un economista más homogéneo $y$ verdaderamente economista, lo cual podría implicar la reducción de su numero con una correspondiente mayor calldad. Especificamente, esta permeabilidad debe realizarse en tres frentes: primero, es necesario transparentar el mercado a tra- 
vés de una mayor informaclón, Inducelón y selección en la ensenianza secundaria; scgundo, en el transcurso de la formación del estudiante debe existir un lazo conla realldad social para promover a su vez la formación de un cludadano y captar todos los cambios del medio; y tercero, hay que darle posición al economista próximo agraduarse tanto frente a las demás profesiones como frente a la comunidad, y brindarle la oportunidad

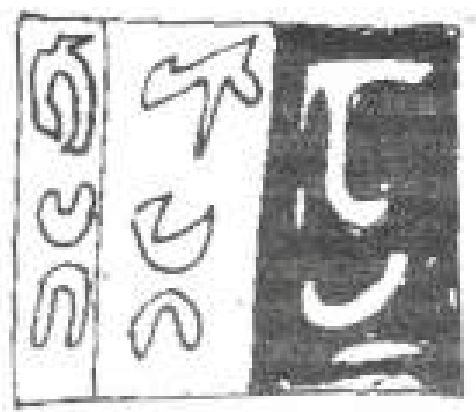
de iniciar su desempeño a través de trabajos prácticos. 